\title{
The Drill to Get the Stent In: A Case Report of Successful Rotational Atherectomy in a Patient Presenting with STEMI
}

\author{
Daniel Mascarenhas ${ }^{1 *}$, Rohit Masih ${ }^{2}$ and Gary Costacurta ${ }^{2}$ \\ 1Department of Cardiology, Easton Hospital, USA \\ 2Department of Medicine, Easton Hospital, USA
}

Submission: July 03, 2019; Published: July 17, 2019

*Corresponding author: Daniel Mascarenhas, Department of Medicine, Division of Cardiology, Easton Hospital, USA

Keywords: Angioplasty; Rotational atherectomy; Coronary artery; Myocardial infarction

Abbreviations: RA: Rotational Atherectomy; ACS: Acute Coronary Syndrome; STEMI: ST-Elevation of Myocardial Infarction; CAD: Coronary Artery Disease; CABG: Coronary Artery Bypass Grafting; LIMA: Left Internal Mammary Artery; LAD: Left Anterior Descending; RCA: Right Coronary Artery; ECG: Electrocardiogram; TIMI: Thrombolysis in Myocardial Infarction; IABP: Intra-Aortic Balloon Pump; PCI: Percutaneous Coronary Intervention; DES: Drug Eluting Stent; TTE: Transthoracic Echocardiogram

\section{Introduction}

Rotational atherectomy (RA) was introduced in the late 1980 s and emerged in the 1990 s as an additional tool to aid in recanalization of obstructed coronary vessels. Today, RA use is infrequent due to increased development in management of stable ischemic heart disease. Although, it has shown to be an effective strategy in acute coronary syndrome (ACS) [1], in the event of a ST-elevation of myocardial infarction (STEMI), the application of RA is contraindicated due to the risk of platelet activation by the Rotablator and has only been described in a few cases $[2,3]$. Here, we describe a case demonstrating the use of RA to aid in revascularization of the culprit vessel in a patient presenting with STEMI after abrupt occlusion of its vein graft.

Case Description

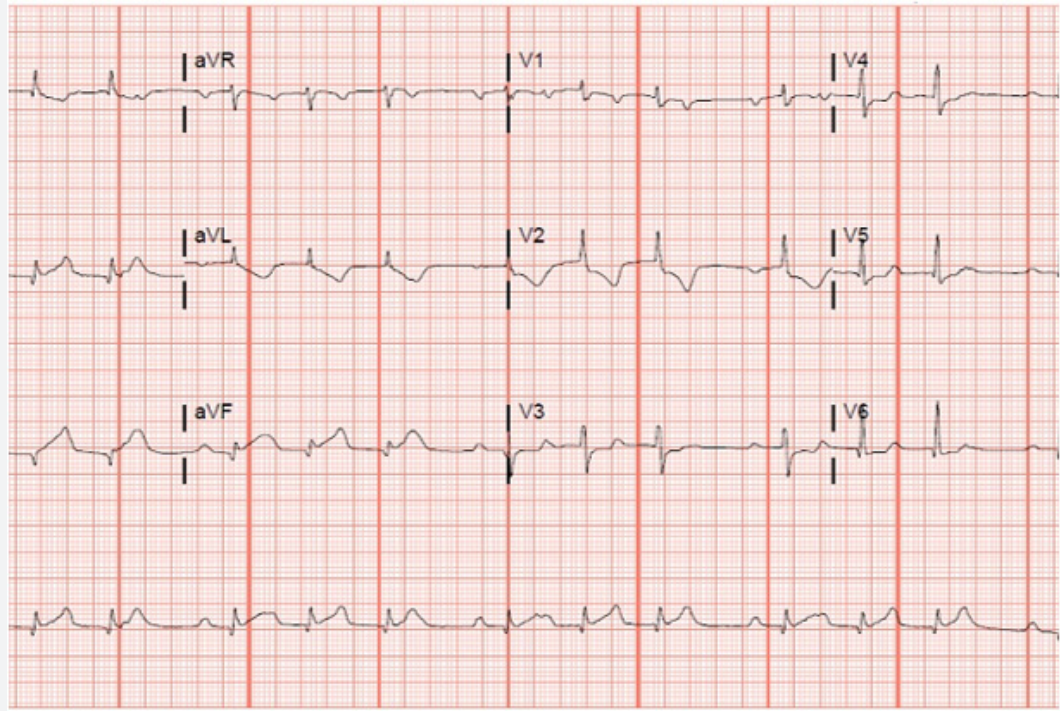

Figure 1: 


\section{Journal of Cardiology \& Cardiovascular Therapy}

A 69 year old female with a past medical history of coronary artery disease (CAD) who underwent coronary artery bypass grafting (CABG) with left internal mammary artery (LIMA) to the left anterior descending (LAD), vein graft to the right coronary artery (RCA) and vein graft to the obtuse marginal, one month prior, presented to the emergency department (ED) with complaint of chest pain.

On physical examination, patient was in moderate distress and diaphoretic. Cardio-vascular examination revealed normal heart sounds with an S3 and a 2/6 systolic ejection murmur along the left sternal border. Lungs revealed bibasilar crackles.

Electrocardiogram (ECG) revealed sinus rhythm with 2nd degree type 1 heart block and evidence of ST segment elevation in leads II, III and aVF (Figure 1), suggestive of inferior wall STEMI. Initial labs demonstrated a troponin of $2.85 \mathrm{ng} / \mathrm{ml}$, BNP 631 . White blood cell counts $8.6 / \mathrm{uL}$, hemoglobin $11.4 \mathrm{GM} / \mathrm{dL}$, platelets 372,000. Metabolic panel showed sodium of $129 \mathrm{mmol} / \mathrm{L}$, potassium $3.7 \mathrm{mEq} / \mathrm{L}$, blood urea nitrogen $18 \mathrm{mg} / \mathrm{dL}$, creatinine $0.97 \mathrm{mg} / \mathrm{dL}$.

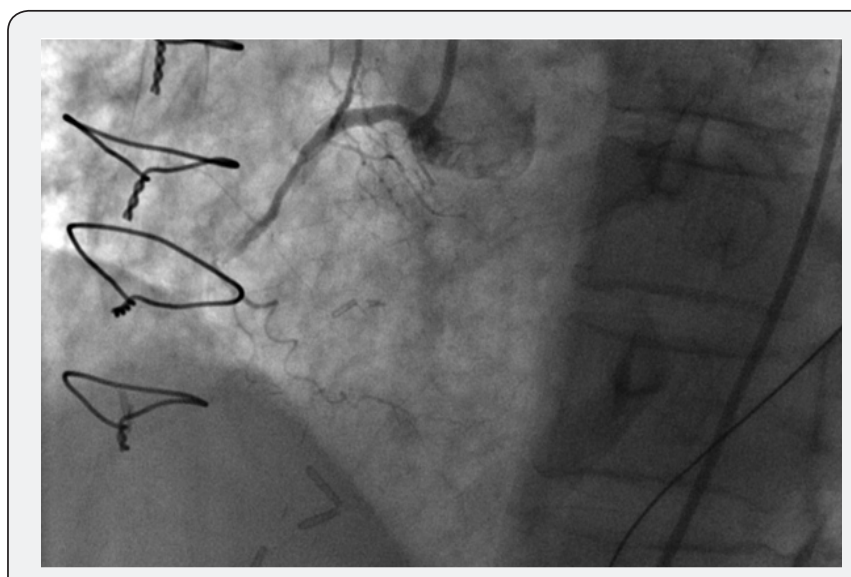

Figure 2

She was taken emergently for cardiac catheterization and diagnostic angiography showed total occlusion of the RCA (Figure 2) in the midportion with "Thrombolysis in Myocardial Infarction" (TIMI) flow 0 and total occlusion of the vein grafts to the RCA and obtuse marginal branch. At this point, patient became hemodynamically un-stable, hence underwent intra-aortic balloon pump (IABP) placement.

The RCA demonstrated severe atherosclerosis and moderate calcifications. After multiple unsuccessful attempts at percutaneous coronary intervention (PCI) (Figures 3), it was decided to use RA (Figure 4). Using a $1.50 \mathrm{~mm}$ Rota Link Plus with $167,000-181,000 \mathrm{rpm}$, two runs of RA were performed successfully and eventually a drug eluting stent (DES) was placed with post-stent residual narrowing of less than 10\% (Figure 5) and total resolution of symptoms. The patient was subsequently started on aspirin and prasugrel.

Transthoracic echocardiogram (TTE) demonstrated mildly decreased left ventricular systolic function with an ejection fraction of $45 \%$, mild concentric left ventricular hypertrophy, moderate mitral annular calcifications and mitral regurgitation. Patient's right ventricular size and function was preserved.

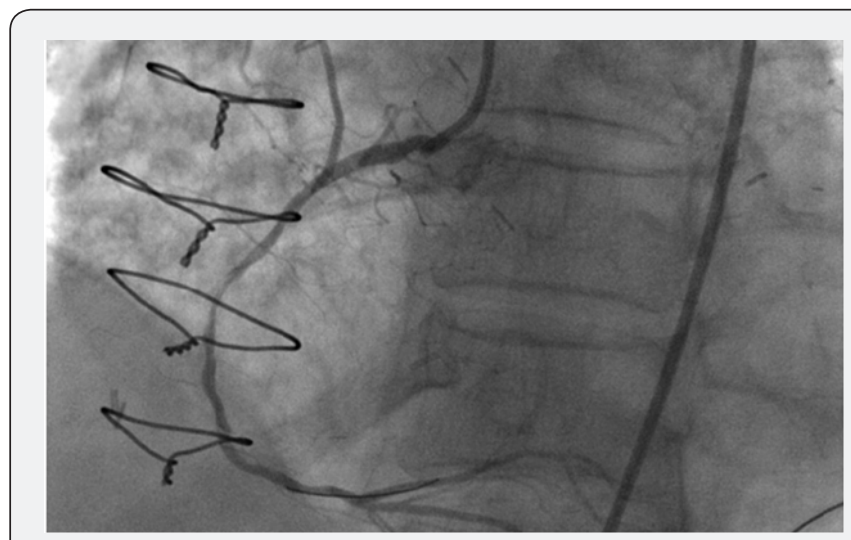

Figure 3

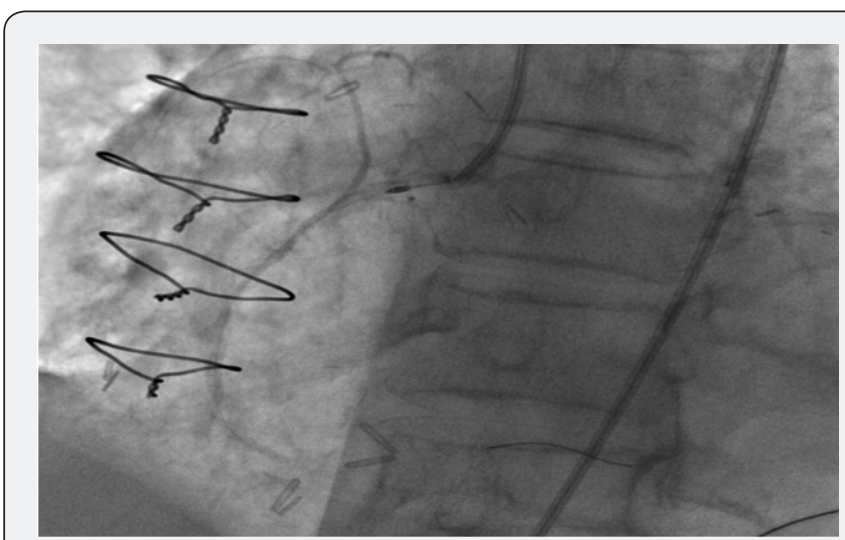

Figure 4

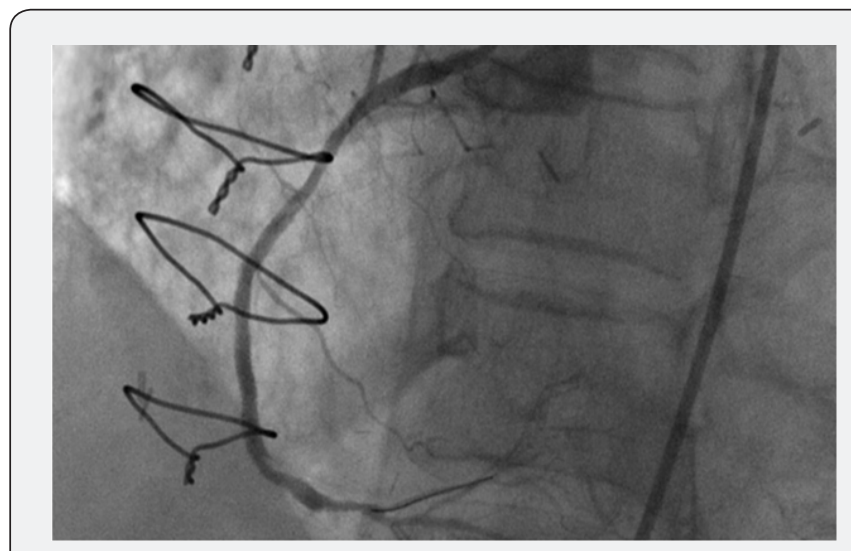

Figure 5

\section{Discussion}

Rotational atherectomy has been shown to be an effective strategy in ACS [1], how-ever, RA is generally avoided in STEMI patients given the concern for slow or no-reflow phenomenon. This is observed most commonly during saphenous vein graft intervention, rotational atherectomy and primary PCI for acute STEMI [4]. 
Since its introduction, RA use has decreased significantly due to newer methods of PCI with RA use involved in PCI as low as $1 \%$ [5]. Despite these concerns associated with RA, its off-label use is being used more frequently [6]. More than $60 \%$ of patients were in the off-label group in this analysis of 250 patients. Interestingly, only $19 \%$ of these patients had RCA intervention.

Our case highlights the importance of RA as an alternative option for revascularization in a high-risk patient. RA may be considered in a patient with STEMI when standard interventions are unsuccessful. In our patient, it proved to be a lifesaving procedure. Advances in pharmacological and procedural techniques [7-9] have contributed to the success of RA in many cases reviewed in literature.

\section{Conclusion}

When standard interventions fail, rotational atherectomy may serve as an alternative option in patients with STEMI. Operator experience and comfort with rotational atherectomy is extremely important. We believe this technique should be maintained in specialized centers to manage high risk patients who present with disease not amenable to other methods of PCI.

\section{References}

1. Doshi SN, Kini A, Kim MC, Payne N, Kamran M, et al. (2003) A com- parative study of rotational atherectomy in acute and stable coronary syndromes in the modern era. Am J Cardiol 92(12): 1404-1408.

2. Ho PC (2005) Rotational coronary atherectomy in acute ST-segment elevation myocardial infarction. J Interven Cardiol 18(4): 315-318.

3. Hussain F, Golian M (2011) Desperate times, desperate measures: rotablating dissections in acute myocardial infarction. J Invasive Cardiol 23(9): E226-E228.

4. van Gaal WJ, Banning AP (2007) Percutaneous coronary intervention and the no-reflow phenomenon. Expert Rev Cardiovasc Ther 5(4): 715-731.

5. Mota P, Santos R, Pereira H, et al. (2013) Facts on rotational atherectomy for coronary artery disease: multicentric registry (abstr). Paper presented at: EuroPCR Paris, France.

6. Sakakura K, Ako J, Wada H, Naito R, Funayama H, et al. (2012) Comparison of frequency of complications with on-label versus off-label use of rotational atherectomy. Am J Cardiol 110(4): 498-501.

7. Kini A, Marmur JD, Duvvuri S, Dangas G, Choudhary S, et al. (1999) Rotational atherectomy: improved procedural outcome with evolution of technique and equipment. Single-center results of first 1,000 patients. Catheter Cardiovasc Interv 46(3): 305-311.

8. Reisman M, Shuman BJ, Dillard D, Fei R, Misser K, et al. (1998) Analysis of low-speed rotational atherectomy for the reduction of platelet aggregation. Cathet Cardiovasc Diagn 45(2): 208-214.

9. Reisman M, Shuman BJ, Harms V (1998) Analysis of heat generation during rotational atherectomy using different operational techniques. Cathet Cardiovasc Diagn 44(4): 453-455.

\begin{tabular}{l} 
Your next submission with Juniper Publishers \\
will reach you the below assets \\
- Quality Editorial service \\
- Swift Peer Review \\
- Reprints availability \\
- E-prints Service \\
- Manuscript Podcast for convenient understanding \\
- Global attainment for your research \\
- Manuscript accessibility in different formats \\
( Pdf, E-pub, Full Text, Audio) \\
- Unceasing customer service \\
Track the below URL for one-step submission \\
https://juniperpublishers.com/online-submission.php \\
\hline
\end{tabular}

